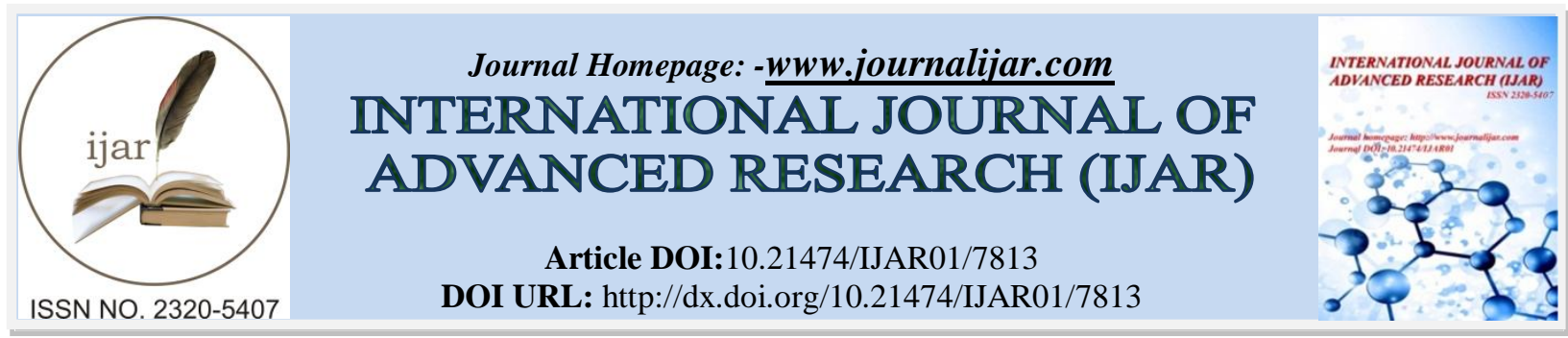

RESEARCH ARTICLE

\title{
APPLICABILITY OF RISK OF MALIGNANCY INDEX IV FOR SCREENING MALIGNANT OVARIAN MASS AMONG PATIENT WITH ADNEXAL MASS AND ITS COMPARISION WITH OTHER RISK OF MALIGNANCY INDEXES.
}

Dr. Smrutishree Sahoo, Dr. Sujata Singh, Dr. Lucy Das and Dr. Sasmita Swain.

Department of Obstetrics' and Gynaecology, S.C.B. Medical College and Hospital, Cuttack, Odisha, India.

\section{Manuscript Info}

Manuscript History

Received: 5 August 2018

Final Accepted: 7 September 2018

Published: October 2018

\section{Abstract}

Background:Adnexal masses are common gynaecological conditions and might be encountered at every stage of a woman life. As presentation of ovarian cancer is very vague ovarian malignancies are called as "SILENT KILLERS". So patients presenting with adnexal mass needs to be preoperatively evaluated and screened for malignancy. Risk of Malignancy Index(RMI) is a combination screening method which utilises menopausal status, CA125 level and ultrasound findings to predict whether an adnexal mass is benign or malignant.

Aim and Objective:The aim of the study is to evaluate the ability of RMI 4 to discriminate between benign and malignant adnexal mass and to compare it with RMI1, RMI2 and RMI3.

MATERIAL AND METHODS- It is a prospective study done over a period from July 2015 to January 2018. Total 124 patients were included in study. Data regarding menopausal status, ultrasound features, size of lesion and CA125level were collected. RMI4 was calculated for each patient. Collected data was analyzed by comparing the means and the differences between groups and assessed with Student's t test and $\chi 2$ test where necessary.

Result: In present study, RMI4 was found to be a statistically significant as a screening agent for discriminating benign from malignant adnexal mass. The cut off value for RMI4 was found to be 450 with sensitivity, specificity, positive predictive value of $68.3 \%$, $84.4 \%$ and $80.4 \%$ respectively. When comparing effectiveness of RMI4 with other RMIs; RMI4 had a higher specificity compared to others like RMI1(82.8\%), RMI2(82.8\%) and RMI3(81.3\%) but sensitivity of RMI2 (70\%) is more than RMI4(68.3\%).

Conclusion: Ovarian cancer has become fourth most common cancer in India. India being a low resource country, identification of a malignant lesion at peripheral level pre-operatively will help in prompt referral to gynecological oncology centers.

Copy Right, IJAR, 2018,. All rights reserved. 


\section{Introduction:-}

Adnexal masses are common gynaecological conditions and might be encountered at every stage of a woman life. The age specific incidence rate (ASIR) found that ovarian cancers increases from 35 years and peaks around 55-64 years. As presentation of ovarian cancer is very vague with symptoms like bloating, pelvic or abdominal pain , poor appetite, urinary urgency; ovarian malignancies are called as "SILENT KILLERS".

On general outdoor basis, pelvic mass is an important and common finding. Pelvic masses needs to be differentiated as benign or malignant. Preoperative evaluation is essential so that if found to be malignant referral to gynaecologic oncology can be done. Recent studies have shown that surgery by gynaec-oncologist has better survival ${ }^{1}$. Pelvic masses so identified can be from female reproductive system or from other adnexal structures. Pelvic masses from female reproductive structures can be from ovarian, fallopian tubes, uterus, broad ligament, cervix. Among these pelvic masses of ovarian origin is most common. In premenopausal females upto $24 \%$ of ovarian mass are found to be malignant while in menopausal women upto $60 \%$ can be malignant.

Various methods for distinguishing benign from malignant mass exits. This includes clinical examination(by history and abdomino-pelvic examination), ultrasound, CTscan, biochemical variables. The sensitivities and specificities of each of these methods are low. Hence combination methods are formulated to have higher sensitivity and specificity and less false positive and false negative values.

Risk of Malignancy Index(RMI) is one such combination screening method which utilises menopausal status, CA125 level and ultrasound findings to predict whether an adnexal mass is benign or malignant. This particular idea is beneficial in low resource developing countries like India where suspecting malignancy referral to gynaeconcology is beneficial for patient. RMI was came into light in 1990 when Jacob et al which is called as RMI ${ }^{2}$. Later in 1996, Tingulstad et al modified it and developed RMI $2^{3}$. It was again modified by Tingulstad in 1999 and is called $\mathrm{RMI}^{4}$. In 2009, Yorritoyammamoto et al developed RMI4 ${ }^{5}$.

\section{Material AndMethods:-}

The main source of data for the study were patients from SCB Medical College, Cuttack. This was a prospective study. Total 124 patients with adnexal mass were included in the study. The study was done over a period from July 2015 to January 2018. All patients presenting with sonographic or other radiological \& clinical features of adnexal mass to gynaecology OPD were evaluated with CA-125 level (pathology),pelvic USG with Doppler and menopausal status was noted. Postmenopausal women are defined as more than one year of amenorrhoea or surgical menopause after 50 years of age. The RMI were calculated using following formulae-

1. $\quad$ RMI $1\left(\right.$ Jacobs et $\left.\mathrm{al}^{2}\right)=\mathrm{U} * \mathrm{M} * \mathrm{CA} 125$;

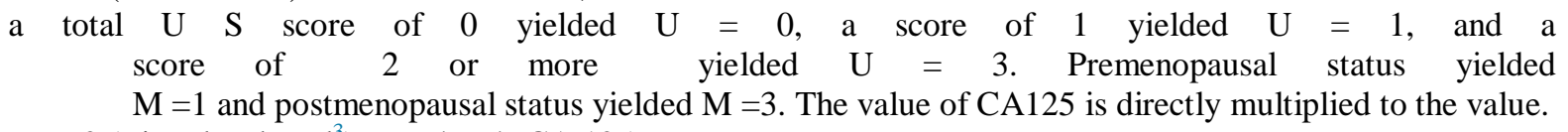

2. RMI 2 (Tingulstad et $\left.\mathrm{al}^{3}\right)=\mathrm{U} * \mathrm{M} * \mathrm{CA} 125$;

a total US score of 0 or 1 yielded $U=1$ and a score of 2 or more yielded $\mathrm{U}=4$. Premenopausal status yielded $\mathrm{M}=1$ and postmenopausal status yielded $\mathrm{M}=4$. The serum level of CA125 was applied directly to the calculation.

3. RMI 3 (Tingulstad et $\left.\mathrm{al}^{4}\right)=\mathrm{U}^{*} \mathrm{M}^{*}$ CA 125 ;

a total US score of 0 or 1 yielded $U=1$ and a score of 2 or more yielded $U=3$. Premenopausal status yielded $M$ $=1$ and postmenopausal status yielded $\mathrm{M}=3$. The serum CA 125 level was applied directly to the calculation.

4. Risk of malignancy index 4 (RMI 4) is calculated basing on following criteria-RMI $4=\mathrm{U} * \mathrm{M} * \mathrm{~S} * \mathrm{CA}-125$

$\mathrm{U}$ score 0 or 1 then $\mathrm{U}=1$ and if score $>=2$ then $\mathrm{U}=4$

$\mathrm{M}$ for premenopausal $\mathrm{M}=1$, postmenopausal $\mathrm{M}=4$

$\mathrm{S}=$ size of tumor ( single greatest diameter calculated by either USG/CT/MRI-), if $\langle 7 \mathrm{~cm} \mathrm{~S}=1$ if $\rangle=7 \mathrm{~cm}$ then $\mathrm{S}=2$ $\mathrm{U}=$ ultrasound score(Presence of multilocular cystic lesion, solid areas, bilateral lesions, ascites \&intraabdominal metastasis. 1 point is given to each feature). Pre-operative serum level of CA-125 was applied directly to the calculation. Histopathological diagnosis was regarded as a definite outcome. Gynaecological cancers was staged as per FIGO staging. 


\section{Inclusion criteria:-}

All new cases of adnexal mass presenting to gynaecology OPD of all age groups.

Exclusion criteria:-

Cases of adnexal mass already on treatment, follow up cases, adnexal mass with pregnancy were excluded.

Collected data were analysed by comparing the means and the differences between groups and assessed with Student's t test and $\chi 2$ test where necessary. The relationship between parameters assessed by stepwise multiple linear regression. A probability of $\leq 0.05$ was considered as statistically significant. After taking informed verbal consent all patients included in the study had undergone thorough clinical and necessary radiological, biochemical investigations. After diagnosis was made a definite surgical management was carried out.

\section{Results:-}

Out of total 124 patients 60 cases were found to be malignant and 64 cases were benign. Mean age of presentation of malignancy was 39 year and benign was. Most common age group presenting with malignancy was above 50 years. Among premenopausal women $37.5 \%$ were malignant while among postmenopausal women $85.71 \%$ were malignant. Most common symptom among both malignant(60\% cases) and benign( $82.8 \%)$ disease was pain abdomen.

Other symptoms in malignant conditions were abdominal distension(13.33\%), bloating(11.66\%), early satiety and weight loss $(10 \%)$ in decreasing order. The comparison between ultrasound scores with histopathology findings were done and shown in TABLE1. A comparision between size of mass as determined radiological examination and histopathology was done. Statistical analysis done using chi-square test and found that size alone does not statistically significant correlate with malignancy $(\mathrm{p}=0.400)$. The distribution of cases as per histopathological findings shown in TABLE2. The distribution of cases with CA125 taken as cutoff of 35IU/ml is shown in TABLE3. Out of all malignant cases $73.3 \%$ cases were in Stage I, $11.53 \%$ in Stage II, $13.46 \%$ in Stage III and 5.76\% in Stage IV. Analysis was done about probability of malignancy that can be predicted by either physical examination alone or in combination with CA125 or in combination with ultrasound features. The sensitivity and specificity on combining physical examination(P.E.) with CA125 was $87 \%$ and $32 \%$ respectively. The sensitivity and specificity on combining physical examination with ultrasound was $67 \%$ and $68 \%$ respectively. On checking the statistical significance of these correlation it was found to be statistically significant ( $p$ value $<0.0001$ ). Thus on combining CA125 or ultrasound to P.E. increases the chances of detecting benign from malignant conditions.

For RMI1, best performance obtained at 200 with sensitivity, specificity, positive predictive value and negative predictive value of $66.7 \%, 82.8 \%, 78.4 \%$ and $72.6 \%$ respectively. For RMI2, best performance obtained at 250 with sensitivity, specificity, positive predictive value and negative predictive value of $70 \%, 82.8 \%, 79.2 \%$ and $74.6 \%$ respectively. For RMI3, best performance obtained at 200 with sensitivity, specificity, positive predictive value and negative predictive value of $66.7 \%, 81.3 \%, 76.9 \%$ and $72.2 \%$ respectively. For RMI4, best performance obtained at 450 with sensitivity, specificity, positive predictive value and negative predictive value of $68.3 \%, 84.4 \%, 80.4 \%$ and $74 \%$ respectively.

By two tailed test p value of RMI1, RMI2, RMI3, RMI4 and CA125 were calculated and found to be statistically significant $(p<0.0001)$. ROC analysis of RMI1, RMI2, RMI3 and RMI4 showed significantly high values for area under curve, with value of $0.821,0.821,0.813,0.820$ respectively. Value for area under curve for CA125 was 0.752 . Thus, RMI1, RMI2, RMI3, RMI4, CA125 are demonstrated to have good ability to predict and identify benign from malignant pelvic masses. However, present study showed no statistically significant difference in performance of RMI1, RMI2, RMI3, RMI4.

Table 1:-ComparisionBetween Different Ultrasound Findings With Histopathological Findings

\begin{tabular}{|l|l|l|l|}
\hline Ultrasound findings & Benign & Malignant & Total cases \\
\hline 0 & 8 & 0 & 0 \\
\hline 1 & 41 & 18 & 59 \\
\hline$>=2$ & 21 & 36 & 57 \\
\hline
\end{tabular}


USG score of $0,1, \geq 2$ was correlated with prediction of malignancy. A univariate analysis was done to find statistical significance using Chi-square test. The $\mathrm{p}$ value $=0.0001$. Therefore it was deciphered from present study that with increase in USG score the chances of malignancy increases.

Table 2:-Table Showing Distribution Of Cases As Per Histopathological Types In Present Study

\begin{tabular}{|l|l|l|l|}
\hline Benign & \multicolumn{3}{|l|}{ Malignant } \\
\hline Mature cystic teratoma & $21(16.93 \%)$ & Serous adenocarcinoma & $18(14.51 \%)$ \\
\hline Mucinous cystadenoma & $15(12.09 \%)$ & $\begin{array}{l}\text { Mucinous } \\
\text { cystadenocarcinoma }\end{array}$ & $9(7.25 \%)$ \\
\hline Serous cystadenoma & $4(3.22 \%)$ & Granulosa cell tumor & $2(1.61 \%)$ \\
\hline Chocolate cyst & $12(9.67 \%)$ & Yolk sac tumor & $7(5.64 \%)$ \\
\hline Simple ovarian cyst & $7(5.64 \%)$ & Dysgerminoma & $6(4.83 \%)$ \\
\hline Ovarian leiomyoma & $3(2.41 \%)$ & Immature teratoma & $4(3.22 \%)$ \\
\hline Tuberculouspyosalphinx & $1(0.80 \%)$ & Non hodgkin lymphoma & $2(1.61 \%)$ \\
\hline Broad ligament fibroid & $1(0.80 \%)$ & $\begin{array}{l}\text { Endometroid } \\
\text { adenocarcinoma }\end{array}$ & $1(0.80 \%)$ \\
\hline & & Alveolar adenocarcinoma & $1(0.80 \%)$ \\
\hline & & $\begin{array}{l}\text { Metastatic } \\
\text { adenocarcinoma }\end{array}$ & $1(0.80 \%)$ \\
\hline & Malignant brenner tumor & $1(0.80 \%)$ \\
\hline & Borderline serous & $4(3.22 \%)$ \\
\hline & Borderline mucinous & $4(3.22 \%)$ \\
\hline
\end{tabular}

Most common benign lesion in present study is mature cystic teratoma.

Most common malignant lesion is serous cystadenocarcinoma.

Table 3:-Distribution Of Cases If Serum Ca125 Cutoff Taken At 35iu/Ml (As Formulated By Bast Et Al ${ }^{27}$

\begin{tabular}{|l|l|l|l|}
\hline Ca125 & Benign & Malignant & Total cases \\
\hline$<35 \mathrm{iu} / \mathrm{ml}$ & 21 & 11 & $32(25.8 \%)$ \\
\hline$>=35 \mathrm{iu} / \mathrm{ml}$ & 43 & 51 & $94(75.8 \%)$ \\
\hline
\end{tabular}

Mean serum CA125 for malignant lesions is $496.87 \mathrm{IU} / \mathrm{ml}$.

Mean serum CA125 for benign lesions is $38.33 \mathrm{IU} / \mathrm{ml}$.

\section{Discussion:-}

For effectiveness of a screening programme, for early detection of disease certain criteria need to be fulfilled. These includes-

1. The disease must have an identifiable phase of early invasive disease, so that diagnosis at this stage and appropriate management helps in overall survival.

2. Disease must be significant threat to society.

3. The testing modality must be sensitive enough to detect small volume of disease.

4. Most importantly, specificity should be high so that individuals without disease can be accurately identified.

Ovarian cancer fulfils all the above criteria and hence requires screening. High specificity becomes important in ovarian cancer screening programme as operative procedure are required for confirmation. Ovarian cancer screening test requires high specificity therefore, a cut off has been chosen with high specificity with modest sensitivity. These will prevent benign tumours from referring to gynaec-oncologist and unnecessary increasing their load.

Ideally, false negative rate of a screening test must be zero or close to zero ${ }^{50}$. But in our present studytotal false negative test are 19 cases. Out of this majority of cases are germ cell tumours like dysgerminoma ( 5 cases), yolk sac tumor ( 4 cases), immature teratoma ( 2 cases). Others includes serous cystadenocarcinoma( 2 cases), mucinous cystadenocarcinoma ( 2 cases), malignant Brenner tumour (1 case) and borderline serous tumours ( 2 cases). Following false negative cases reflects that CA125 test are not very helpful in detecting germ cell tumours. Studies conducted by Schutter et $\mathrm{al}^{6}$., Varras et $\mathrm{al}^{7}$ showed ultrasound score increases the chances of malignancy increases. This same finding has also been obtained in present study. 
Simseket al. $(2014)^{8}$ has reported a sensitivity of $78.6 \%$ and specificity of $63.5 \%$ for a CA125 cut-off of $35 \mathrm{U} / \mathrm{ml}$. Bouzari et al $^{9}$ study indicated a sensitivity of $88 \%$ and specificity of $97 \%$ for CA125 at a higher cut-off of $88 \mathrm{U} / \mathrm{ml}$. In study by Dora et $\mathbf{a l}^{10}$, CA125 levels $\geq 35 \mathrm{U} / \mathrm{ml}$ had a sensitivity of $87 \%$, specificity of only $19.3 \%$, positive predictive value of $56.6 \%$, and negative predictive value of 55\% respectively. Best performance of CA-125 in their study was at a cut off of 143 with sensitivity $62.32 \%$, specificity $96.49 \%$, positive predictive value of $93.5 \%$ and negative predictive value of $67.5 \%$. In present study , at serum CA125 value $\geq 35 \mathrm{IU} / \mathrm{ml}$, the sensitivity was $85 \%$, specificity was $32.8 \%$, PPV was $54.26 \%$ whereas NPV was 70\% and diagnostic accuracy was $58.06 \%$. However, best performance of CA125 was obtained at 88IU/ml having sensitivity and specificity of $70 \%$ and $79.7 \%$ respectively. The PPV and NPV were $76.4 \%$ and $73.9 \%$ respectively. Mean serum CA125 for malignant lesions is 496.87IU/ml. Mean serum CA125 for benign lesions is $38.33 \mathrm{IU} / \mathrm{ml}$.

In present study, total 124 cases were taken. Out of these 64 cases $(51.61 \%)$ were diagnosed to have benign condition and $60(48.38 \%)$ cases had malignant condition. Benign conditions includes benign ovarian tumour and other causes of adnexal mass like broad ligament fibroid and tuberculouspyosalpinx. Malignant conditions includes malignant ovarian tumour and borderline ovarian tumour. In present study, most common benign ovarian neoplasm is mature cystic teratoma (21 cases) followed by mucinous cystadenoma(15 cases). Out of 8 cases(13.33\% of malignant cases) of borderline tumor, only in 2 cases RMI4 predicted it as benign.

Mean age of detecting malignant ovarian mass in study by Akdenizet al ${ }^{11}$ was 40.63 years and by Yamamoto et $\mathbf{a l}^{5}$. was 54 years. In present study, mean age for malignant mass was 39 years.

Tingulstadet al. ${ }^{3}$ developed their RMI in 1996 and named it RMI 2. In a direct comparison of their RMI with that developed by Jacobs et $\mathrm{al}^{2}$, they found that, at a cut-off levelof 200, RMI 2 was significantly better than RMI 1 for prediction of malignancy. In our study, we observed sensitivity and specificity of $70 \%$ and $82.8 \%$ at a cut-off level of 250 for RMI 2.

Tingulstadet al. ${ }^{4}$, defined RMI 3 observed that, at a cut-off level of 200, sensitivity and specificity were $71 \%$ and $92 \%$, respectively. In our study RMI 3, we observed a sensitivity and specificity of $66.7 \%$ and $81.3 \%$ at a cut-off level of 200, respectively, which is comparable with results reported by Tingulstadet al. ${ }^{4}$.

In 2009, Yamamoto et al. ${ }^{5}$ developed RMI 4, and confirmed that, at a cut-off level of 450, the accuracy of RMI 4 was better than that of RMI 1, RMI 2, and RMI 3, with a cutoff level of 200. They reported that at a cutoff level of 450, sensitivity, specificity, positive predictive value, negative predictive value were $86.8 \%, 91.0 \%, 63.5 \%$ and $97.5 \%$ respectively. In our study, we observed a sensitivity, specificity, positive predictive value and negative predictive value of $68.3 \%, 84.4 \%, 80.4 \%, 74 \%, \quad$ at a cutoff level of 450 for RMI 4, respectively, which is comparable with results reported by Yamamoto et al. ${ }^{5}$ accept that in our study PPV is higher than Yamamoto et al study. In our study, we also found the other RMIs i.e. RMI 1, RMI 2, RMI 3 showed reliable diagnostic performance, which deferred from results of Yamamoto et al.. Results of a study conducted by Aktürket al. ${ }^{12}$ in 2011, which compared RMI 1, RMI 2, RMI3 and RMI 4, confirmed that there was no statistical difference in benign-malignancy discrimination between these four indices. Similar results are also found in study by Jung-Woo Park, et al ${ }^{13 .}$

\section{Conclusion:-}

RMI 4 is a good screening agent that can be used for pre-operative assessment. At a cut off score of 450 it effectively discriminates a benign from malignant lesion. . Further, on comparing RMI1, RMI2, RMI3 and RMI 4 , it was found that performance of RMI 1, RMI 2 and RMI 4 in differentiating benign from malignant adnexal mass is almost same. RMI 3 performance was slightly less but not statistically significant. Ultrasound score and CA125 levels were found to have statistically significant ability to predict risk for malignancy. 


\section{References:-}

1. Changing Trends in Incidence of Ovarian Cancer - the Indian Scenario, NandagudiSrinivasaMurthy1 , S Shalini1 , G Suman1, Srekantaiah Pruthvish1, Aleyamma Mathew2, Asian Pacific Journal of Cancer Prevention, , Volume 10, Issue 6, June 2009, Page 1025-1030.

2. Jacobs I, Oram D, Fairbanks J, Turner J, Frost C, Grudzinskas JG. A risk ofmalignancy index incorporating CA 125, ultrasound and menopausal status for theaccurate preoperative diagnosis of ovarian cancer. $\mathrm{Br} \mathrm{J}$ ObstetGynaecol 1990; 97:922-9.

3. Tingulstad S, Hagen B, Skjeldestad FE, et al. Evaluation of risk of malignancyindex based on serum CA 125, ultrasound findings and menopausal status inthe preoperative diagnosis of pelvic masses. Br J ObstetGynaecol 1996; 103:826-31.

4. Tingulstad S, Hagen B, Skjeldestad FE, Halvorsen T, Nustad K, Onsrud M. Therisk of malignancy index to evaluate potential ovarian cancers in local hospitals. BrJ ObstetGynaecol 1999; 93:448-52

5. Yamamoto Y, Yamada R, Oguri H, Maeda N, Fukaya T. Comparison of fourmalignancy risk indices in the preoperative evaluation of patients with pelvicmasses. Eur J ObstetGynecolReprodBiol 2009; 144:163-7

6. Schutter EM, Kenemans P, Sohn C, Kristen P, Crombach G, Westermann R, et al. Diagnostic value of pelvic examination, ultrasound, and serum CA 125 in postmenopausal women with a pelvic mass. An international multicenter study. Cancer. 1994;74(4):1398-406, doi: 10.1002/10970142(19940815)74:4<1398::AIDCNCR2820740433>3.0.CO;2-J.

7. Varras M. Benefits and limitations of ultrasonographic evaluation of uterine adnexal lesions in early detection of ovarian cancer. Clinical and experimental obstetrics \& gynecology. 2003;31(2):85-98

8. Simsek HS, Tokmak A, Ozgu E, et al. Ole of a risk of malignancy index in clinical approaches to adnexal masses. Asian Pac J Cancer Prev. 2014;15(18): 7793-7

9. Bouzari Z, Yazdani S, Kelagar ZS, Abbaszadeh N. Risk of malignancy index as an evaluation of preoperative pelvic mass. Caspian J Intern Med. 2011;2(4): 331-5.

10. A prospective study to evaluate the risk malignancy index and its diagnostic implication in patients with suspected ovarian mass Santosh Kumar Dora*, AtalBihariDandapat, BenudharPande and Jatindra Prasad Hota, Dora et al. Journal of Ovarian Research (2017) 10:55 DOI 10.1186/s13048-017-0351-2

11. Akdeniz N, Kuyumcuoğlu U, Kale A, Erdemoğlu M, Caca F. Risk of malignancy index for adnexal masses. Eur J GynaecolOncol. 2009;30(2):178-80

12. Comparison of four malignancy risk indices inthe detection of malignant ovarian massesErhanAktürkKazimEmreKarasahin Murat DedeMüfitCemalYenen Article in Journal of Gynecologic Oncology · September 2011 DOI: 10.3802/jgo.2011.22.3.177 · Source: PubMed

13. Jung-Woo Park, MD, Jee-Hyun Park, MD, EunSeop Song, MD, Byoung-Ick Lee, MD, JeongHoon Lee, MD, Ki-Won Kim, MD, Kyoung-Mi Kim, MD, Min-Jae Jung, MD, Nae-Ri Yun, MD, Sung-Ook Hwang, MD, FOUR RISK OF MALIGNANCY INDICES IN EVALUATION OFPELVIC MASSES, Korean J ObstetGynecol 2012;55(9):636-643http://dx.doi.org/10.5468/KJOG.2012.55.9.636, pISSN 2233-5188 · eISSN 2233-5196. 